\title{
Gender Variation in Extracurricular Activity Participation and Perceived Life Chances in Trinidad and Tobago Adolescents
}

\section{Variación por Sexo de la Participación en Actividades Extracurriculares y la Percepción de Oportunidades de Vida en Adolescentes de Trinidad y Tobago}

\author{
Zena R. Mello y Frank C. Worrell \\ University of California
}

\begin{abstract}
Participation in extracurricular activities has surfaced as an important context for adolescent development and may be a fruitful avenue for fostering future attitudes, a concept shown to predict adolescent behaviors. In this study of youth from Trinidad and Tobago, we examined gender differences in activity participation and perceived life chances in 1,385 adolescents $(59 \%$ male). Trinidadian adolescents were highly active, on average, participating in three activities. More males were involved in athletic and organized groups, whereas more females participated in artistic and religious activities. Artistic and athletic activity participation predicted positive perceived life chances, even after controlling for academic achievement. Artistic activities were especially beneficial for predicting future attitudes for males compared to females.
\end{abstract}

Keywords: gender variation, extracurricular activities, perceived life chances, future-orientation, Trinidad and Tobago, adolescents.

\begin{abstract}
La participación en actividades extracurriculares es un importante contexto para el desarrollo adolescente y puede ser una provechosa vía para promover actitudes acerca del futuro, un concepto que permite predecir el comportamiento adolescente. En esta investigación se examinaron las diferencias por sexo de la participación en actividades y la percepción de las oportunidades de vida en 1.385 adolescentes de Trinidad y Tobago (59\% varones). Los adolescentes eran muy activos, participando en promedio en tres actividades. Los hombres participaban más en deportes y grupos organizados, mientras las mujeres lo hacían en actividades artísticas y religiosas. La participación en actividades artísticas y deportivas predijo una percepción positiva sobre las oportunidades de vida, aun después de controlar los logros académicos. Las actividades artísticas fueron especialmente beneficiosas para predecir las actitudes de los hombres respecto del futuro.
\end{abstract}

Palabras clave: variación por sexo, actividades extracurriculares, percepción de oportunidades de vida, orientación futura, Trinidad y Tobago, adolescentes.

Introduction

Trinidad and Tobago is a twin island republic in the southern Caribbean with a population of a little over one million people. Despite a vibrant economy

Zena R. Mello, Cognition and Development, University of California, Berkeley, United States.

Frank C. Worrell, Cognition and Development, University of California, Berkeley, United States.

Correspondence concerning this article should be addressed to Zena R. Mello, Ph.D., Cognition and Development, University of California, 4511 Tolman Hall, Berkeley, CA, United States. E-mail:mello@berkeley.edu

The study was conducted under the auspices of the School Leadership Center of Trinidad and Tobago.

The authors would like to thank Rebecca Anguiano for translation services. and the highest per capita income in the Caribbean, poverty is widespread and rising (World Bank, 2000; Worrell, 2006a). Poverty rates are highly correlated to educational attainment among Trinidadian youth. For example, in 1998 less than half the student population passed the general or basic proficiency exams in English and Mathematics (Worrell, 2006a). As a point of comparison, Trinidadian poverty rates are comparable to those reported for ethnic minority youth in the United States (US). Estimates indicate that about $33 \%$ of Trinidadian youth receive public assistance (Worrell, 2006a) compared to $40 \%$ of Hispanic and African American youth (National Adolescent Health Information Center, 2003). Further, some reports show that important indicators such as youth literacy and school drop out rates 
have worsened over time (Guttman, 1994; Webster \& Ganpat, 2006). Given these patterns, it is important for researchers to investigate factors that may promote positive developmental outcomes in Trinidadian youth. In fact, international programmatic efforts have been developed to promote self-awareness and positive future attitudes in Trinidad and Tobago adolescents (Griffith, 2002; Guttman, 1994), and the government has stated goals of substantially increasing educational participation rates (Government of the Republic of Trinidad and Tobago, 2005).

Research indicates that extracurricular activities provide an important context for adolescent development (Feinstein, Brynner, \& Duckworth, 2006; Mahoney, Harris, \& Eccles, 2006) and participation in these activities may prove fruitful in promoting positive outcomes in Trinidadian youth. Indeed, in an effort to foster healthy development in youth, the government has established youth centers that promote athletic, artistic, and musical activities such as steel drum bands (Griffith, 2002; Guttman, 1994; World Bank, 2000). Extracurricular activities have been consistently associated with academic achievement in general adolescent populations (Mahoney et al., 2006) and groups of socioeconomically disadvantaged youth (Boratav, 2005; Mahoney, Lord, \& Carry, 2005). Further, a study of US adolescents showed that participation in extracurricular activities was linked to future expectations regarding schooling (Darling, 2005). Future-oriented concepts have been consistently shown to predict academic outcomes (Nurmi, 1991), and have been highlighted as an important factor in fostering educational outcomes in marginalized youth, in particular (Phalet, Andriessen, \& Lens, 2004). Importantly, gender variation has been shown in both extracurricular activities (Eccles, Barber, Stone, \& Hunt, 2003; Feldman \& Matjasko, 2005) and in thoughts about the future (Eccles \& Wigfield, 2002; Mello, 2008). Thus, in this study we examined how involvement in extracurricular activities predicted future attitudes in Trinidadian youth and how such a relationship varied by gender.

\section{Extracurricular Activities}

Theoretical perspectives suggest that adolescents benefit from extracurricular activity participation through several processes, including engagement in prosocial activities, observing positive role models, or having access to a safe place to spend time (Boratav, 2005; Eccles \& Barber, 1999; Mahoney et al., 2006). Other perspectives propose that academic-related benefits may occur through learning how to focus and structure time with extracurricular activities (Chin \& Harrington, 2007). For example, Chin and Harrington (2007) discussed the potential benefits of studying music, such as fine motor development, learning to focus attention, and improve social skills. Even further, some researchers argue that participation in extracurricular activities may play an especially important role in the lives of adolescents who face challenges due to economic or social situations, because the benefits of activity participation may offset such challenges (Boratav, 2005; Guttman, 1994). Thus, from all of these perspectives, youth residing in Trinidad and Tobago may benefit from extracurricular activity participation.

Extracurricular activities refer to involvement in organized groups or activities such as dance, football, and student government and may occur in or outside of school. In Trinidad, extracurricular activities are an important part of adolescent life. There are national competitions celebrating adolescents' performance in a variety of activities including football (soccer), cricket, drama, and debating (Worrell \& Bucknavage, 2004). Reports of Trinidadian youth indicate that a majority participate in some extracurricular activity. In fact, in one study, $75 \%$ of the youth reported that they participated in at least one activity (Guttman, 1994). This finding parallels results from studies with US adolescents which show that about $75 \%$ participate in at least one activity (Feldman \& Matjasko, 2005).

However, the types of activities that adolescents engage vary across nations. In a study of US adolescents, Eccles et al. (2003) identified over 40 activities that adolescents participate in a regular basis. Activities included prosocial and religious experiences, such as volunteering and church attendance, performance activities such as drama, dance and band, and school activities such as student government, chess clubs, and science clubs. In the US, athletics are the most frequently studied activities (Bucknavage \& Worrell, 2005) and the most commonly reported by adolescents (Feldman \& Matjasko, 2005; Worrell \& Bucknavage, 2004). In support of this statement, Larson and Verma (1999) discussed how European adolescents spend more time playing music, whereas US adolescents spend more time playing sports. Feldman and Matjasko (2005) also indicated that about $25 \%$ of partici- 
pants in a US national study reported participating in musical or dramatic clubs, whereas about $15 \%$ participated in service or professional clubs.

Research on adolescent extracurricular activities from nations other than the US indicates that such participation predicts important developmental outcomes. In a study of how Scottish adolescents spend time, Sweeting and West (2003) found that adolescents with more unstructured time were more likely to engage in substance use than their counterparts. Boratav (2005) showed that organized sports provided economically disadvantaged Turkish youth, especially males, with an opportunity to engage in prosocial activities. Feinstein et al. (2006) reported that adolescents' participation in youth clubs, described as organized centers outside of school, predicted lower adult unemployment, crime and substance use, in a sample of British youth.

Participation in extracurricular activities has been consistently and positively associated with academic outcomes among adolescent populations in the US (Feldman \& Matjasko, 2005; Mahoney et al., 2006). In a longitudinal study of adolescents in $7^{\text {th }}$ through $12^{\text {th }}$ grade, Mahoney and Cairns (1997) showed that participation in extracurricular activities reduced the likelihood of dropping out of high school, and Davalos, Chavez, and Guardiola (1999) found that adolescents who participated in extracurricular activities were 2.3 times more likely to be enrolled in high school than their counterparts. Similarly, Eccles et al. (2003) reported that adolescents who participated in extracurricular activities in high school had higher academic achievement and were more likely to attend and graduate from college than their counterparts who did not participate in extracurricular activities. Mahoney et al. (2005) reported that academic performance were significantly higher among youth who participated in after-school programs compared to their counterparts, and Bucknavage and Worrell (2005) indicated that $93 \%$ of academically talented youth participate in extracurricular activities.

The relationship between extracurricular activity participation and developmental outcomes varies with the type of extracurricular activity. Eccles and Barber (1999) showed that participation in activities such as church attendance and volunteer work is directly associated with academic achievement and inversely associated with engagement in risky behavior. Participation in the performance arts is positively related to academic achievement, whereas participation in athletics is positively related to both alcohol use and academic achievement. In a more recent study, participation in both athletic and nonathletic activities was positively associated with academic achievement (Guest \& Schneider, 2003). In a study of young adolescents, results showed that higher musical involvement was significantly associated with higher educational and occupational expectations (Denny, 2007).

Most intriguing and relevant to the present study are findings from research that show how engaging in extracurricular activities are positively associated with future attitudes. Guest and Schneider (2003) reported that participation in non-athletic activities such as music and drama clubs or student government was positively associated with both academic achievement and educational expectations. Similarly, in a longitudinal study of ethnically diverse high school students, Darling (2005) reported that participation in extracurricular activities predicted favorable attitudes towards school and educational aspirations.

Less attention has been directed to the relationship between participation in extracurricular activities and problem behavior, although extant research shows a significant inverse association. In a representative sample of Caribbean youth, researchers observed that participation in extracurricular activities reduced engagement in risky behavior such as substance use (Blum, Halcon, Beuhring, Pate, Campell-Forrester, \& Venema, 2003). In a longitudinal study of US adolescents, participation in extracurricular activities also predicted lower rates of alcohol and substance use (Eccles et al., 2003). Most recently, Darling (2005) showed an inverse association between self-reported substance use and participation in extracurricular activities.

\section{Perceived Life Chances}

Perceived life chances refer to individuals' expectations that future positive events will occur in educational, occupational, familial, and community domains, and are conceptually similar to future attitudes, a cognitive-motivational construct that refers to individuals' orientation and attitude toward the future (Mello \& Worrell, 2006; Nurmi, 1991). Researchers have shown that future attitudes are associated with both positive and negative developmental outcomes (Honora, 2002; Phalet et al., 2004). In a study of high school students, Darling (2005) found that participation in extracurricular activities, such as 
band, cheerleading, and academic clubs, positively predicted educational aspirations.

Other research suggests that developing positive attitudes towards the future can be deliberately fostered in youth. For example, Danish (1997) taught adolescents how to identify and attain positive life goals, and Oyserman, Terry, and Bybee (2002) developed an intervention program which prompted adolescents to think about their future through activities such as imagining adulthood and connecting current behavior with future attainment. Results from both of these studies indicated that adolescents receiving the intervention reported higher school engagement and better school attendance than their non-intervention counterparts.

Research with Trinidadian populations indicates that adolescents report positive attitudes toward the future. A study of individuals surveyed at ages 16 and 22 showed that participants were generally optimistic at 16 , with more than half of the sample expecting to have an intermediate or high nonmanual occupation, although only $4 \%$ had obtained such a position by age 22 (Mustapha, 1994). Another report on Trinidad and Tobago youth participating in a youth program showed that a majority had positive aspirations about obtaining employment, owning a house, and getting married (Griffith, 2002).

Research with American populations has shown that children growing up in high-risk settings who reported positive expectations had better academic adjustment three years later compared to their counterparts with negative future expectations (Wyman, Cowen, Work, \& Kerley, 1993). This finding is replicated in adolescent and adult samples. In a study of college students, Zimbardo and Boyd (1999) reported a positive association between thinking about the future, grade point average, and hours of studying per week. In another study, at-risk students who believed that their future would be fine graduated from high school at higher rates than equally at-risk peers who did not share this hope (Worrell \& Hale, 2001).

Future attitudes are also related to problem behaviors. In research with ethnically diverse adolescents, future time perspective was inversely associated with substance use, exposure to violence, and victimization (Doucette-Gates, 1999). Positive perceived life chances also predicted lower rates of binge drinking among low-income African American and Hispanic adolescents (Griffin, Botvin, Nichols, \& Scheier, 2004). Lastly, in a study of college students, positive future attitudes were inversely associated with risky driving (Zimbardo, Keough \& Boyd, 1997), although the relationship was weak.

\section{Gender}

Gender differences have been reported in extracurricular involvement and in future attitudes. In their international review of involvement in extracurricular activities, Larson and Verma (1999) reported that, in nonindustrial nations, males had more time to participate in leisure-time activities than females, whereas in industrialized nations, females and males did not differ in the time available to participate in these types of activities. Research in the US indicates that adolescent females are likely to participate in more extracurricular activities than males (Eccles et al., 2003; Feldman \& Matjasko, 2005). With regard to type of extracurricular activity, females participate in more diverse activities than males, whereas males participate in more athletics than females, and this finding holds across national boundaries (Bucknavage \& Worrell, 2005; Eccles \& Barber, 1999; Eccles et al., 2003; Feldman \& Matjasko, 2005; Larson \& Verma, 1999). In analyses of Swedish adolescents, Sweeting and West (2003) reported that gender variation was observed in the ways that adolescents spent leisure time, with more females engaging in shopping and listening to music, and more males participating in athletics-related activities. Most recently, Martinez, Cumsille, and Thibaut (2007) reported that adolescent females in Chile were more involved in prosocial and civic activities than Chilean adolescent males.

With regard to future attitudes, research on gender differences has yielded mixed results, with findings from the earliest studies favoring males, others favoring females, and others showing no differences between the genders. McCabe and Barnett (2000) reported no gender differences in future attitudes among adolescents. Similarly, a report on adolescents in Trinidad and Tobago indicated that females and males were equally likely to express future plans (Griffith, 2002). However, in 1983, Trommsdorff reported that females expressed more pessimistic thoughts about the future than males, who reported more optimistic thoughts. Wyman et al. (1993) also reported that males held more positive future expectations than females. In a study of Canadian adolescents, Andres, Anisef, Krahn, Looker, and Thessen (1999) reported that females' future 
attitudes actually increased during challenges in the labor market. In other studies (e.g., Honora, 2002; Mello \& Worrell, 2006), females have reported less negative attitudes about the future than males. The inconsistent findings could be related to differences in the way that future attitudes were operationalized across studies.

\section{Present Study}

The purpose of the present study was to examine Trinidadian adolescents' participation in extracurricular activities in relation to their perceived life chances and gender. This study was guided by several research questions. First, at what rate do Trinidadian adolescents participate in extracurricular activities? We expected a high rate of participation due to Trinidadian cultural attitudes (Worrell \& Bucknavage, 2004). Second, how do Trinidadian adolescents perceive their future? Given the dearth of research with this population, we did not make hypotheses. Third, how do Trinidadian females and males vary in perceived life chances and extracurricular activities? Given the mixed findings in prior research (Mello \& Worrell, 2006), we did not make formal predictions about gender differences in perceived life chances, although we expected males to participate in more athletic activities, consistent with prior international research (Larson \& Verma, 1999). Fourth, how does participation in extracurricular activities relate to future attitudes? Based on a recent study (Darling, 2005), we expected a direct association between participation in extracurricular activities and perceived life chances.

Method

\section{Participants}

The initial sample included 1,738 adolescents attending secondary schools in Trinidad. Participants were a convenient sample recruited from secondary schools in Trinidad. Schools were identified through their membership with the School Leadership Center of Trinidad and Tobago. Twelve schools agreed to participate in the study that included grades six through ten. The geographic location of the schools was diverse, with six in the north, five in the south, and one in the central area. Some cases had miss- ing values for key variables such as perceived life chances $(n=108)$ or extracurricular activities $(n=$ 278) and were thus excluded from the present study. The final sample consisted of 1,385 adolescents. Participants were aged 11 to $19(M=14.48, S D=1.75)$ with more than half of the sample aged 13 to 15 . The sample was $59 \%$ male $(n=797)$. Self-reported ethnic groups included African descent $(n=323,24 \%)$, East Indian descent $(n=511,38 \%)$, mixed descent $(n=409,31 \%)$, Syrian/Lebanese descent $(n=10$, $0.75 \%)$, White/Caucasian descent $(n=47,4 \%)$, and other descent $(n=34,3 \%)$. Fifty-one participants had missing values for ethnic group.

\section{Measures}

Extracurricular activities. Individuals were asked to indicate if they participated in 19 extracurricular activities with a yes or no response to each item. In accordance with prior research (Eccles et al., 2003), extracurricular activities were grouped into categories based on similarity and responses were summed. Categories included athletic (football, hockey, basketball/netball, cricket, swimming, table tennis), artistic (dance, solo instrumental music, choir music, steel band music, drama/acting, and photography), intellectual (student council, debating, chess, junior achievers), religious (religious clubs), and organized groups (Scouts, Cadets). A total extracurricular activity participation score was generated by summing all yes responses.

Perceived life chances. The Measure of Perceived Life Chances ([MPLC] Jessor, Donovan, \& Costa, 1990) is a unidimensional measure that assesses the subjective likelihood of a number of future events. The original measure included 10 items beginning with the prompt What are the chances that...? and ending with statements such as ...you will graduate from high school, ...you will have a happy family life, and ... you will be respected in your community. Items were rated on a 5-point Likert scale ranging from 1 (very low) to 5 (very high). The two educational items were changed to adapt the measure to Trinidad. The item on graduating from high school was reworded to What are the chances that you will get at least 5 CXC [Caribbean Examination Council] passes?, reflecting the minimum number considered adequate for a complete certificate, and the item on going to college was reworded to What 
are the chances that you will go to university or get professional qualifications? As the Trinidadian educational system has two years (advanced) after the CXC exams required for entering a local or British university, a question was also added to reflect this: What are the chances that you will go on to 'A' [Advanced] Levels? Finally, a global item on the future was added that had proved useful in prior research on future attitudes (Worrell \& Hale, 2001): What are the chances that your future will work out the way you want it to? The unidimensionality of the revised 12-item measure was supported in an exploratory factor analysis, and the reliability estimate for scores was 0.82 . A total score was generated by summing items with a higher score indicating a more positive future attitude. MPLC scores could range from 12 to 60 .

Academic achievement. Academic achievement was self-reported by participants. Students were asked to provide a global sense of their achievement using a six-point Likert-scale corresponding to the following grades: $80 \%$ or above (6), $70-79 \%(5)$, $60-69 \%$ (4), 50-59\% (3), 40-49\% (2), and below $40 \%$ (1). The Trinidadian academic grading system is based on percent calculated across all subject areas. There is no grade point average (GPA) as there is in the US.

\section{Procedure}

Participants were recruited from secondary schools in Trinidad. Schools were identified through their association with the School Leadership Center of Trinidad and Tobago. Teachers administered the questionnaires, which were completed anonymously. Completed questionnaires were collected by the Center. A list of extracurricular activities was generated by two psychologists, a high school principal, and a teacher trainer. The study was approved by the Institutional Review Board of the Pennsylvania State University.

Results

\section{Extracurricular Activity Participation}

Trinidadian adolescents reported participation in many extracurricular activities (see Table 1). The majority participated in at least one extracurricular activity $(n=1,190,85 \%)$, half participated in one to three activities, and over a third in more than four activities. On average, adolescents participated in about three extracurricular activities. The most popular activities were athletics, followed by artistic, intellectual, religious, and organized groups such as Cadets. Extracurricular activity participation was

Table 1

Trinidadian Adolescents' Extracurricular Activity Participation by Activity Type and Level $(N=1,385)$

\begin{tabular}{lcc}
\hline \multicolumn{1}{c}{ Extracurricular Activity } & Number of Activities $^{\mathrm{a}}$ & Percentage \\
\hline Activity Type & 6 & 66 \\
Athletic & 6 & 51 \\
Artistic & 4 & 28 \\
Intellectual & 1 & 26 \\
Religious & 2 & 15 \\
Organized Groups & 0 & \\
Activity Level & & 14 \\
No Participation & $1-3$ & 50 \\
Average Participation & $4-19$ & 35 \\
High Participation & & \\
\hline
\end{tabular}

Note. ${ }^{\text {a }}$ Indicates the quantity of extracurricular actives included in each activity type. See Measure section for details on specific activities included in each activity type. ${ }^{b}$ Value calculated across activity types. 
associated with academic achievement. The total number of extracurricular activities adolescents participated in was positively associated with academic achievement $(r=0.24, p<0.01)$, although the relationship is modest. Participating in athletic $(r=-0.08, p<0.01)$ and intellectual $(r=0.08, p<$ $0.01)$ activities had significant inverse and positive relationships with academic achievement, respectively, but, as can be seen, the relationships were essentially zero, with significance due to sample size. There was no association between participation in artistic, religious, and group activities and academic achievement. Participants' age was not associated with athletic, intellectual, or religious activities, although older students were more likely to participate in athletic activities $t(1374)=3.83, p$ $<0.001, d=0.30$ (Non-participants' $M=14.01, S D$ $=1.67$; Participants' $M=14.51, S D=1.70$ ).

\section{Perceived Life Chances}

Participants reported positive attitudes about the future, with an average MPLC score of 4.18 (SD $=0.52$ ), above the mid-point of the scale (i.e., 3). Perceived life chances were positively associated with academic achievement $(r=0.24, p<0.001)$, although the relationship was modest. Correlations indicated that participation in overall extracurricular activities was positively associated with perceived life chances $(r=0.12, p<0.001)$ and with most particular activities: athletic $(r=0.09, p<0.01)$, artistic $(r=0.09, p<0.01)$, intellectual $(r=0.09$, $p<0.001)$, and religious activities $(r=0.08, p<$ $0.001)$. However, all relationships had small effect sizes. Perceived life chances were also not associated with participating in organized groups such as Cadets and Scouts $(r=0.01, p=0.70)$. Participants' age was inversely associated with perceived life chances $(r=-0.13, p<0.001)$, but this relationship was also practically not significant.

\section{Gender Variation}

As hypothesized, gender was significantly associated with both extracurricular activities and perceived life chances. As Figure 1 shows, males participated in more athletic activities $t(1350)=8.82, p$ $<0.001, d=0.49$, than females, who participated in more artistic activities $t(1350)=8.34, p<0.001, d$ $=0.46$, than males. Although other differences were significant (e.g., organized groups, $t[1350]=1.65, p$ $<0.001, d=0.09$; religious groups, $t[1350]=2.37$, $p<0.01, d=0.13$; perceived life chances, $t[1582]$ $=-3.00, p<0.01, d=0.20)$, the small effect sizes indicate that there are no meaningful differences between the genders on these variables.

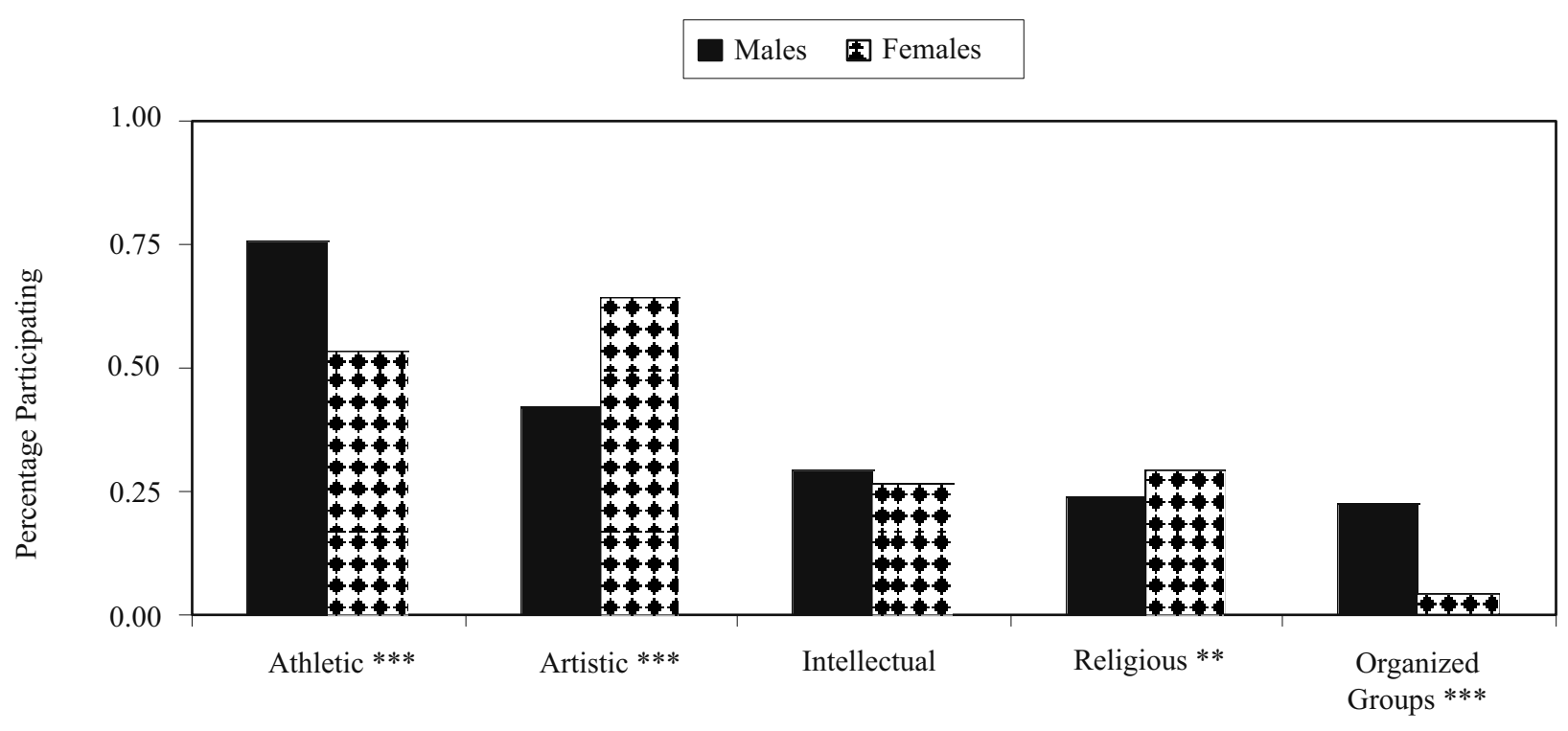

Extracurricular Activities

Figure 1. Gender differences in Trinidadian adolescents' participation in extracurricular activities. $* * p<0.01, * * * p<0.001$. 
Extracurricular Activity Participation, Perceived Life Chances, and Gender

As shown in Table 2, regression analyses indicated that, after controlling for academic achievement, participating in overall, artistic, or athletic activities was associated with an increase in positive future attitudes. However, the standardized coefficients indicate that academic achievement was a stronger predictor of perceived life chances than gender and participation in extracurricular activities. Further, the relationship between extracurricular activity and perceived life chances varied by gender. Figure 2 shows the relationship between females and males who report low and high levels of participation in artistic activities (i.e., one versus five activities) with perceived life chances (estimates shown in Table 2). As illustrated, males who participated in one artistic activity reported the lowest perceived life chances compared to females and males who reported higher levels of participation. It is worth noting that analyses were conducted to determine if academic achievement moderated the relationship between extracurricular activity participation and perceived life chances. Results indicated that academic achievement did not moderate such a relationship (values not shown).

Table 2

Predicting Perceived Life Chances with Participation in Extracurricular Activities and Gender, Controlling for Academic Achievement $(N=1,274)^{a}$

\begin{tabular}{|c|c|c|c|c|c|c|c|c|c|}
\hline & \multicolumn{3}{|c|}{ Overall } & \multicolumn{3}{|c|}{ Artistic } & \multicolumn{3}{|c|}{ Athletic } \\
\hline & $B$ & $S E B$ & $\beta$ & $B$ & $S E B$ & $\beta$ & B & $S E B$ & $\beta$ \\
\hline Extracurricular Activity & $0.42 * * *$ & 0.09 & 0.17 & $0.83 * * *$ & 0.21 & 0.15 & $0.62 * * *$ & 0.15 & 0.14 \\
\hline Gender & 0.59 & 0.36 & 0.05 & $1.48 * *$ & 0.46 & 0.12 & $1.37 * *$ & 0.48 & 0.11 \\
\hline Gender X Activity & $-0.32 *$ & 0.13 & -0.09 & $-0.99 * *$ & 0.30 & 0.16 & -0.25 & 0.27 & -0.04 \\
\hline Academic Achievement & $1.38 * * *$ & 0.16 & 0.24 & $1.39 * * *$ & 0.16 & 0.24 & $1.39 * * *$ & 0.16 & 0.24 \\
\hline Intercept & $42.60 * * *$ & 0.76 & & $43.29 * * *$ & 0.72 & & $42.82 * * *$ & 0.76 & \\
\hline$R^{2}$ & 0.08 & & & 0.07 & & & 0.07 & & \\
\hline \multirow[t]{3}{*}{$F$} & 28.05 & & & $25.79 * * *$ & & & $26.81 * * *$ & & \\
\hline & \multicolumn{3}{|c|}{ Intellectual } & \multicolumn{3}{|c|}{ Organized Groups } & \multicolumn{3}{|c|}{ Religious } \\
\hline & $B$ & $S E B$ & $\beta$ & $B$ & $S E B$ & $\beta$ & $B$ & $S E B$ & $\beta$ \\
\hline Extracurricular Activity & 0.79 & 0.35 & 0.08 & 0.28 & 0.51 & 0.02 & 0.76 & 0.53 & 0.05 \\
\hline Gender & 0.87 & 0.40 & 0.07 & 0.74 & 1.94 & 0.06 & 0.71 & 0.41 & 0.06 \\
\hline Gender X Activity & -0.35 & 0.55 & -0.02 & 0.66 & 0.49 & 0.01 & -0.17 & 0.79 & -0.01 \\
\hline Academic Achievement & $1.33 * * *$ & 0.16 & 0.23 & $1.36 * * *$ & 8.36 & 0.23 & $1.37 * * *$ & 0.16 & 0.23 \\
\hline Intercept & $43.84 * * *$ & 0.71 & & $43.94 * * *$ & 0.71 & & $3.81 * * *$ & 0.72 & \\
\hline$R^{2}$ & 0.06 & & & 0.06 & & & 0.06 & & \\
\hline$F$ & $23.16^{* * *}$ & & & $21.74 * * *$ & & & $22.34 * * *$ & & \\
\hline
\end{tabular}

Note. $B$ : unstandardized beta, $S E B$ : standard error of beta, $\beta$ : standardardized beta. Adjusted $R^{2}$ shown. Gender coded Male $=0$, Female $=1$. ${ }^{a}$ Reduction in sample size by 111 due to missing cases for academic achievement. See Measure section for a description of activities included in each activity type.

$* * p<0.01, * * * p<0.001$.

\section{Discussion}

In this study, we sought to extend knowledge on extracurricular activity participation, given its importance as a domain of adolescent development (Mahoney et al., 2006), and its association with positive outcomes among adolescents who face economic challenges (Boratav, 2005; Eccles \& Barber, 1999; Mahoney et al., 2006). Thus, we focused this study on the connection between participation in extracurricular activities and perceived life chances, a future-oriented concept, shown to predict adolescent behaviors (Jessor et al., 1990). Findings indicated that Trinidadian adolescents participated in many activities and that participation in artistic and athletic activities predicted positive future attitudes. Gender differences emerged for extracurricular activities, for future attitudes, and for the association between artistic activities and future attitudes. 


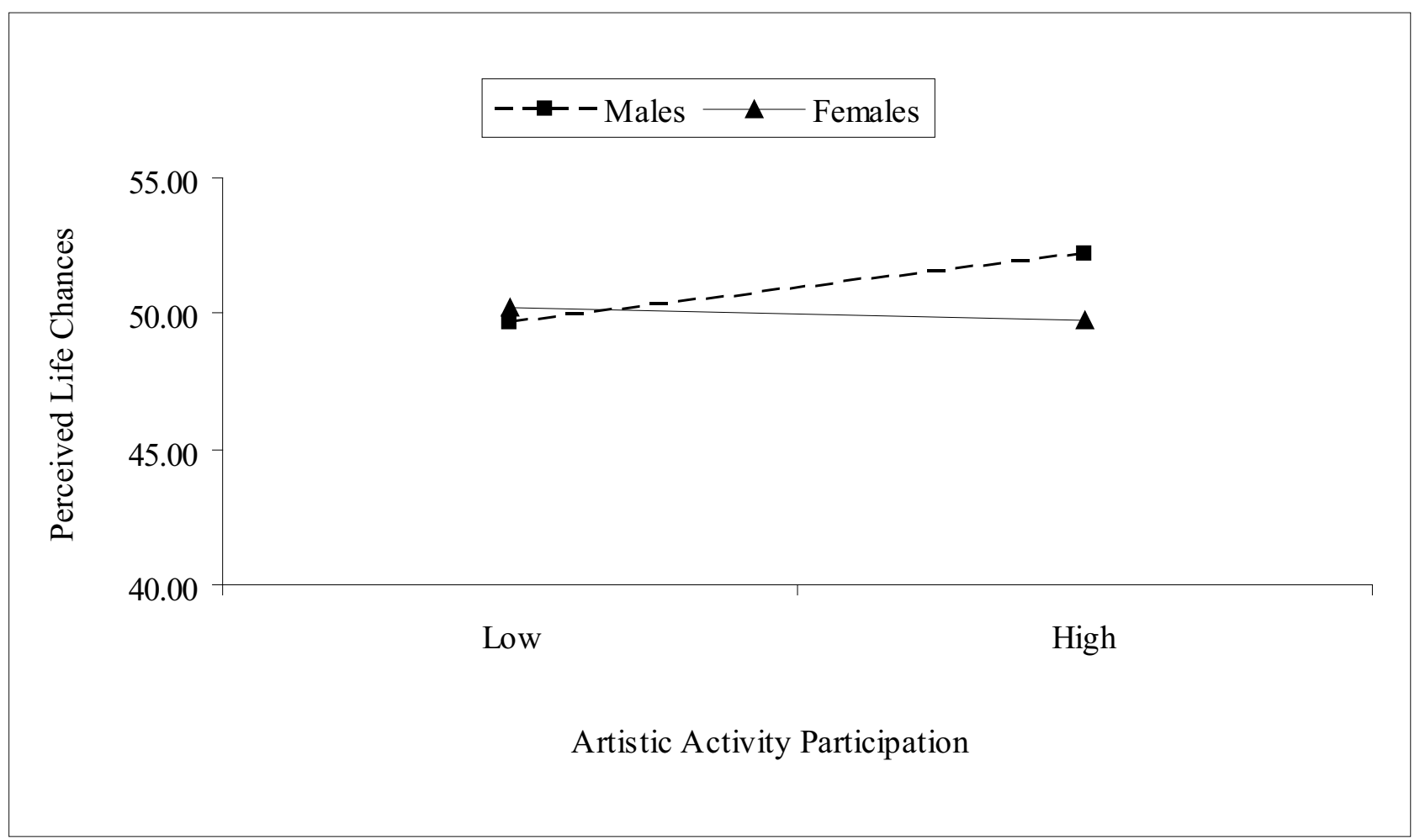

Figure 2. Predicting perceived life chances with extracurricular activity participation level and gender. Note. Low and high participation estimates for adolescents who engage in one and four artistic extracurricular activities, respectively.

Findings from this study extend prior research on extracurricular activities to include a Trinidadian adolescent population. Analyses indicated that the majority of Trinidadian adolescents in this study participated in at least one extracurricular activity (i.e., 86\%). The percentage of Trinidadian adolescents participating in activities is higher than reports from US samples, which indicate that about $75 \%$ of adolescents engage in such activities (Feldman \& Matjasko, 2005). On average, Trinidadian adolescents reported involvement in three activities compared to only one or two from reports on US samples (Eccles et al., 2003). Overall, Trinidadian adolescents participated in many extracurricular activities. This finding is consistent with Trinidadian cultural attitudes that promote participation in extracurricular activities among youth (Worrell \& Bucknavage, 2004).

\section{Extracurricular Activity Participation and Perceived Life Chances}

Results from this study broaden the association between participation in extracurricular activities and positive developmental outcomes (Mahoney et al., 2006) to include future attitudes. Findings indicated that participation in artistic and athletic experiences positively predicted perceived life chances, even after controlling for academic achievement, although the size of the effects were quite small. Findings are in keeping with prior research that has shown how positive future attitudes may be enhanced through participation in intervention programs (Danish, 1997; Oyserman et al., 2002). Research on this topic may prove to have educational import, given the literature underscoring the value of future-oriented variables in facilitating educational attainment in the US (Phalet et al., 2004).

This study showed that Trinidadian adolescents perceived the future to be positive. This finding is similar to some prior research with adolescents residing in rural Trinidad and Tobago (Mustapha, 1994) and adolescents in Canada (Andres et al., 1999), Turkey (Boratav, 2005), and Scotland (Sweeting \& West, 2003). Similar positive future attitudes have been observed with US adolescents (Mello, in press; Nurmi, 1991) and emerging adults (Arnett, 2000). 
Gender

Gender variation was observed in both extracurricular activity participation and future attitudes. More males participated in athletic and organized activities, whereas more females participated in artistic and religious activities. Gender differences in activity participation among Trinidadian adolescents are in contrast to reports showing that females participate in more overall extracurricular activities compared to males in the US (Eccles et al., 2003) and in more prosocial and civic activities among Chilean adolescents (Martinez et al., 2007). However, consistent with some research (Eccles et al., 2003), Trinidadian males participated in more athletic activities than females. These findings highlight the variability among nations and genders in how adolescents spend time inside and outside of school.

Males reported somewhat more negative perceived life chances than their female counterparts, although the effect was small. This finding is consistent with prior research on US adolescents (Honora, 2002; Mello, 2008; Mello \& Worrell, 2006) and with discussions on the declining developmental outcomes of Caribbean males, in particular (Noguera \& Worrell, 1998; Worrell, 2006b). Caribbean males exhibit more overall problem behaviors than their female counterparts (Ohene, Ireland, \& Blum, 2005; Worrell, 2006b). Implications of such findings are far-reaching. A statement from a 15 year-old Caribbean male highlights concerns about the future: "I' $m$ afraid of life after school. What is it like? What if I do not achieve a career and achieve all of my goals in life?" (Payne, 1988). Research examining gender differences in attitudes toward the future and the potential impact of these attitudes on positive and negative developmental outcomes is needed.

Males who participated in few artistic activities reported lower perceived life chances than females and their male counterparts who participated in more artistic activities. This result is similar to one reported in a study of American adolescents. The US study revealed that males who participated in the performing arts were less likely to use alcohol or skip classes compared to females and males who did not participate in such activities (Eccles \& Barber, 1999). Taken together, these findings suggest that participation in artistic activities may be especially beneficial for males. Indeed, in a recent review of school-based extracurricular activities, Feldman and Marjasko (2005) argued that an important direction for research in this area is to examine engagement in various types of activities.

\section{Limitations and Future Directions}

Limitations of this study include conceptual, design, and measurement issues. Although this study make a contribution to our understanding of extracurricular activity participation and future-oriented thoughts, there are several concepts that were not assessed that may have contributed to a greater understanding of this area. Such concepts include the length of time that adolescents participated in particular activities, the reasons or motivation for adolescents to seek such participation, and characteristics of the adults involved in the activities. The primary limitation of this study was the use of correlational data. Given that all data were collected at one point in time, causal inferences cannot be drawn from the results. Although adolescents' future attitudes were associated with participation in extracurricular activities, it is not clear if the attitudes preceded the decision to participate or if participation resulted in a change in attitudes. Longitudinal studies that examine future attitudes across childhood and adolescence and that link future attitudes and participation in extracurricular activities in adolescence with developmental outcomes in adulthood are greatly needed.

Second, self-reported participation in extracurricular activities and perceived life chances were the major variables. There are limitations to relying exclusively on self-report data. The use of multiple informants may provide a more comprehensive understanding of adolescent extracurricular activity participation. Future research should corroborate adolescent self-reports with reports by peers, parents, and teachers. Another direction for future research centers on the role of family in providing opportunities for adolescents to engage in extracurricular activities. Previous research with Trinidad and Tobago youth has underscored the role of family structure in predicting important developmental outcomes such as self-esteem (Holman \& Woodroffe-Patrick, 1988) and provides support for the inclusion of the family in research on activities. 


\section{Conclusion}

Adolescent well-being in Trinidad and Tobago is an important area of research given statistics showing rising poverty and corresponding challenges with educational attainment (World Bank, 2000; Worrell, 2006a). Efforts have targeted the Trinidadian adolescent population with the creation of programs that offer adolescents an opportunity to develop meaningful relationships with adults, hope for the future, and employable skills (Griffith, 2002; Guttman, 1994; Webster \& Ganpat, 2006). A sense of belonging may also be fostered with youth participation in extracurricular activities. The results of this study indicate that participation in some extracurricular activities is related to positive attitudes toward the future, and that such a relationship varies between Trinidadian males and females.

\section{References}

Andres, L., Anisef, P., Krahn, H., Looker, D., \& Thessen, V. (1999). The persistence of social structure: Cohort, class, and gender effects on the occupational aspirations and expectations of Canadian youth. Journal of Youth Studies, 2, 261-282.

Arnett, J. J. (2000). Emerging adulthood: A theory of development from the late teens through the twenties. American Psychologist, 55, 469-480.

Blum, R. W., Halcon, L., Beuhring, T., Pate, E., CampellForrester, S., \& Venema, A. (2003). Adolescent health in the Caribbean: Risk and protective factors. American Journal of Public Health, 93, 456-460.

Boratav, H. B. (2005). Negotiating youth: Growing up in innercity Istanbul. Journal of Youth Studies, 8, 203-220.

Bucknavage, L. B. \& Worrell, F. C. (2005). Academically talented students' participation in extracurricular activities. Journal of Secondary Gifted Education, 16, 74-86.

Chin, C. S. \& Harrington, D. M. (2007). Supporting the development of musical talent. Gifted Child Today, 30(1), 40-47, 65.

Danish, S. J. (1997). Going for the goal: A life skills program for adolescents. In G. W. Albee \& T. P. Gullotta (Eds.), Primary prevention works (Vol. 6, pp. 291-312). Thousand Oaks, CA: Sage.

Darling, N. (2005). Participation in extracurricular activities and adolescent adjustment: Cross-sectional and longitudinal findings. Journal of Youth and Adolescence, 34, 493-505.

Davalos, D. B., Chavez, E. L., \& Guardiola, R. J. (1999). The effects of extracurricular activity, ethnic identification, and perception of school on student dropout rates. Hispanic Journal of Behavioral Sciences, 21, 61-77.

Denny, E. (2007). To what extent does participation in extracurricular music affect the future aspirations of 11-12-year-olds? A small-scale investigation. British Journal of Music Education, 24, 99-115.

Doucette-Gates, A. (1999). Hope sustaining a vision of the future. In C. W. Branch (Ed.), Adolescent gangs: Old issues, new approaches (pp. 57-85). Philadelphia, PA: Brunner/Mazel.
Eccles, J. S. \& Barber, B. L. (1999). Student council, volunteering, basketball, or marching band: What kind of extracurricular involvement matters? Journal of Adolescent Research, 14, 10-43.

Eccles, J. S., Barber, B. L., Stone, M., \& Hunt, J. (2003). Extracurricular activities and adolescent development. Journal of Social Issues, 59, 865-889.

Eccles, J. S. \& Wigfield, A. (2002). Motivational beliefs, values, and goals. Annual Review of Psychology, 53, 109-130.

Feinstein, L., Brynner, J., \& Duckworth, K. (2006). Young people's leisure contexts and their relation to adult outcomes. Journal of Youth Studies, 9, 305-327.

Feldman, A. F. \& Matjasko, J. L. (2005). The role of schoolbased extracurricular activities in adolescent development: A comprehensive review and future directions. Review of Educational Research, 75, 159-210.

Government of the Republic of Trinidad and Tobago (2005). Vision 2020 Operational Plan 2007-2010: Developing innovative people. Port of Spain: Author, Ministry of Planning and Development.

Griffin, K. W., Botvin, G. J., Nichols, T. R., \& Scheier, L. M. (2004). Low perceived chances for success in life and binge drinking among inner-city minority youth. Journal of Adolescent Health, 34, 501-507.

Griffith, J. (2002). To handle life's challenges: A tracer study of Servol's adolescent development programme in Trinidad. Den Haag, Netherlands: Bernard Van Leer Foundation.

Guest, A. \& Schneider, B. (2003). Adolescents' extracurricular activity participation in context: The mediating effects of schools, communities, and identity. Sociology of Education, 76, 89-109.

Guttman, C. (1994). On the right track: Servol's early childhood and adolescent development programming in Trinidad and Tobago. Paris: United Nations.

Holman, T. B. \& Woodroffe-Patrick, M. (1988). Family structure, conflict, and children's self-esteem in Trinidad and Tobago. Journal of Family Issues, 9, 214-223.

Honora, D. T. (2002). The relationship of gender and achievement to future outlook among African American adolescents. Adolescence, 37, 301-316.

Jessor, R., Donovan, J. E., \& Costa, F. (1990). Personality, perceived life chances, and adolescent health behavior. In K. Hurrelmann \& F. Losel (Eds.), Health hazards in adolescence (pp. 25-42). New York: Walter de Gruyter.

Larson, R. W. \& Verma, S. (1999). How children and adolescents spend time across the world: Work, play, and developmental opportunities. Psychological Bulletin, 125, 701-736.

Mahoney, J. L. \& Cairns, R. B. (1997). Do extracurricular activities protect against early school drop out? Developmental Psychology, 33, 241-253.

Mahoney, J. L., Harris, A. L., \& Eccles, J. S. (2006). Organized activity participation, positive youth development, and the over-scheduling hypothesis. Social Policy Report, 20, 3-31.

Mahoney, J. L., Lord, S. E., \& Carryl, E. (2005). An ecological analysis of after-school program participation and the development of academic performance and motivational attributes for disadvantaged children. Child Development, 76, 811-825.

Martinez, M. L., Cumsille, P., \& Thibaut, C. (2007). Chile. In J. J. Arnett (Ed.), International encyclopedia of adolescence (pp. 167-178). New York: Routledge.

McCabe, K. \& Barnett, D. (2000). First comes work, then comes marriage: Future orientation among African American young adolescents. Family Relations, 49, 63-70.

Mello, Z. R. (2008). Gender variation in developmental trajectories of educational and occupational expectations and 
attainment from adolescence to adulthood. Developmental Psychology, 44, 1069-1080.

Mello Z. R. (in press). The development of educational and occupational expectations from adolescence to adulthood in relation to racial/ethnic group and socioeconomic status. Journal of Applied Developmental Psychology.

Mello, Z. R. \& Worrell, F. C. (2006). The relationship of time perspective to age, gender, and academic achievement among academically talented adolescents. Journal for the Education of the Gifted, 29, 271-289.

Mustapha, N. (1994). Youth: Aspirations, expectations, and achievement. New Education, 16, 25-34.

National Adolescent Health Information Center (2003). Fact sheet on demographics: Adolescents. San Francisco, CA: Author.

Noguera, P. A. \& Worrell, F. C. (1998). The crisis of the Black male in the English-speaking Caribbean. Caribbean Perspectives, 1998, 25-31.

Nurmi, J. E. (1991). How do adolescents see their future? A review of the development of future orientation and planning. Developmental Review, 11, 1-59.

Ohene, S. A., Ireland, M., \& Blum, R. W. (2005). The clustering of risk behaviors among Caribbean youth. Maternal and Child Health Journal, 9, 91-100.

Oyserman, D., Terry, K., \& Bybee, D. (2002). A possible selves intervention to enhance school involvement. Journal of Adolescence, 25, 313-326.

Payne, M. A. (1988). Adolescent fears: Some Caribbean findings. Journal of Youth and Adolescence, 17, 255-266.

Phalet, K., Andriessen, I., \& Lens, W. (2004). How future goals enhance motivation and learning in multicultural classrooms. Educational Psychology Review, 16, 59-89.

Sweeting, H. \& West, P. (2003). Young people's leisure and risk-raking behaviours: Changes in gender patterning in the west of Scotland during the 1990s. Journal of Youth Studies, 6, 391-412.

Fecha de recepción: Julio de 2008.

Fecha de aceptación: Octubre de 2008.
Trommsdorff, G. (1983). Future orientation and socialization. International Journal of Psychology, 18, 381-406.

Webster, N. \& Ganpat, W. (2006). Exploring youth development workers in the process of civic youth engagement in Trinidad and Tobago. Journal of International Agricultural and Extension Education, 13(2), 15-25.

World Bank (2000). Trinidad and Tobago youth and social development: An integrated approach to social inclusion (Report $\mathrm{N}^{\circ}$ 20088-TR). Washington, DC: Author.

Worrell, F. C. (2006a). Children and youth in poverty in Trinidad and Tobago: A lack of commitment in the midst of plenty. In C. Yeakey, J. W. Richardson, \& J. B. Buck (Eds.), Suffer the little children: National and international dimensions of child poverty and public policy (pp. 145-176). San Francisco, CA: Elsevier Ltd.

Worrell, F. C. (2006b). Ethnic and gender differences in selfreported achievement and achievement-related attitudes in secondary school students in Trinidad. Caribbean Curriculum, 13, 1-22.

Worrell, F. C. \& Bucknavage, L. B. (2004). Participation in extracurricular activities by students attending assisted and prestige schools in Trinidad. Caribbean Curriculum, 11, 129-147.

Worrell, F. C. \& Hale, R. L. (2001). The relationship of hope in the future and perceived school climate to school completion. School Psychology Quarterly, 16, 370-388.

Wyman, P. A., Cowen, E. L., Work, W. C., \& Kerley, J. H. (1993). The role of children's future expectations in self-system functioning and adjustment to life stress: A perspective study of urban at-risk children. Development and Psychopathology, 5, 649-661.

Zimbardo, P. G. \& Boyd, J. N. (1999). Putting time in perspective: A valid, reliable individual-difference metric. Journal of Personality and Social Psychology, 77, 1271-1288.

Zimbardo, P. G., Keough, K. A., \& Boyd, J. N. (1997). Present time perspective as a predictor of risk driving. Personality and Individual Differences, 23, 1007-1023. 